Research Article

\title{
Sonological Evaluation of Scrotal Pathology by High Resolution Ultrasound and Color Doppler
}

\author{
Narra $\mathbf{R}^{1}$, Pasupuleti $B^{2}$, Kamaraju SK ${ }^{3}$, Jukuri $\mathbf{N}^{4}$ \\ ${ }^{1}$ Dr Ramakrishna Narra, MD (Radiology), DM (Neuroradiology), Associate Professor, ${ }^{2}$ Dr Bhimeswararao Pasupuleti, \\ MD (Radiology), Professor, ${ }^{3}$ Dr Suseel Kumar Kamaraju, MD (Radiology), FRCR Professor, ${ }^{4}$ Dr Naganarasimharaju \\ Jukuri, Assistant Professor, Department of Radiology. All are affiliated with Katuri Medical College, Katuri Nagar, \\ Chinakondrupadu, NH 16, Guntur, Andhra Pradesh 522019, India
}

Address for Corresponding: Dr Ramakrishna Narra, Email: narra.ramki29@gmail.com

\begin{abstract}
Introduction: The development of sonogram with high frequency linear transducer and color doppler is an important mile stone in evaluating scrotal pathologies. Computed tomography exposes testicles to the radiation and MRI is not so easily available. Therefore ultrasound with color Doppler is the best suited modality for the evaluation of scrotal pathologies as it is simple, noninvasive, reproducible, relatively inexpensive and widely available investigation that will not expose the testis to radiation. Aims and Objectives: To classify (etiologically) and to evaluate various scrotal pathologies using ultrasonography and describe the role of High resolution ultrasound and colour doppler in their diagnosis and differentiation. Materials and Methods: The study was done on 60 patients who were referred to the radiology department by the General Surgery and Urology departments for scrotal ultrasound and Doppler study. This study was conducted between May 2012 to September 2014 at Katuri Medical College and Hospital, Chinnakondrupadu, Guntur. Results : Of the 60 patients studied, incidence of various pathologies were as follows -inflammatory pathology in $26 \%$, congenital in $12 \%$, scrotal hernia in $16 \%$, infertility in $8 \%$, torsion in $7 \%$, tumors in $3.3 \%$, trauma in $3 \%$, and others in 26.7\%. The imaging features of these conditions with differentiating hallmarks are described. Conclusion:High frequency ultrasonography is invaluable in demonstrating normalcy of testes and epididymis in the presence of large hydroceles. High-frequency ultrasonography enables clear demonstration of the morphological alterations associated with acute scrotal inflammatory diseases. Color doppler sonography is highly sensitive in diagnosing acute scrotal pathology and accurately differentiates testicular ischemia /torsion from acute inflammatory conditions.
\end{abstract}

Key words: Ultrasonography, Scrotal pathology, varicocele.

\section{Introduction}

Ultra sound with Color Doppler, Magnetic resonance imaging, testicular angiography and radioisotope studies are now first line of investigations used mainly to investigate various scrotal pathologies [1]. The development of sonogram with high frequency linear transducer and color Doppler is an important mile stone in evaluating scrotal pathologies. Computed tomography exposes testicles to the radiation and MRI is not so easily available [2]. So ultrasound with color Doppler is best suited for evaluation of scrotal pathologies. It is simple, noninvasive, reproducible, widely available, relatively inexpensive investigation that does not expose the testis to radiation [3].

Manuscript received: $2^{\text {nd }}$ Dec 2014

Reviewed: $16^{\text {th }}$ Dec 2014

Author Corrected: $4^{\text {th }}$ Jan 2015

Accepted for Publication: $15^{\text {th }}$ Jan 2015
So we have conducted this study to classify (etiologically) and to evaluate various scrotal pathologies using ultrasonography and describe the role of High resolution ultrasound and colour Doppler in their diagnosis and differentiation.

\section{Materials and Methods}

The study was done on 60 patients who were referred to the radiology department by the General Surgery and Urology departments for scrotal ultrasound and Doppler study. This study was conducted between May 2012 to September 2014 at Katuri Medical college and Hospital Chinnakondrupadu Guntur. Ethical board permission was obtained from the hospital. 
Research Article

In all the cases, a meticulous clinical examination was done prior to the scan and consent was taken.

Color Doppler was performed routinely along with grayscale real time imaging. Additional abdominal scan was done in patients with testicular malignancies to identify any associated lymphadenopathy, and in cases of tubercular epididymo-orchitis to look for ascites and in cases of ectopic or undescended testis. After the scan, these patients were followed up with clinicopathological, surgical, biopsy reports. Follow up scans were performed when clinically indicated.
Equipment: Machine used was Philips Envisor CO2 ultrasound and color Doppler unit and GE Logiq F8, having curvilinear probes of frequency $2.5-5 \mathrm{MHz}$ and linear transducer of frequency $3-12 \mathrm{MHz}$.

Scanning Technique: With the patient in the supine position, the scrotum was supported with a rolled towel or sheath placed between the legs and the penis was placed onto the abdomen and covered with a towel. Scanning was done in the transverse, longitudinal and oblique planes with a $3-12 \mathrm{MHz}$ linear array transducer. Transverse side by side images were used to compare the echogenicity and vascularity of both testes.

Additional positions/maneuvers like standing, valsalva maneouver were used whenever required (as in the evaluation of a varicocele).

Spermatic cord and inguinal regions were scanned in varicocele to know the complete extension and in epididymitis to look for funiculitis and in undescended testis cases. Colour and power Doppler ultrasound were used to detect perfusion and verify abnormal flow patterns.

The spectral waveform of intratesticular arteries characteristically is of low resistance index $(0.48-0.75$; average -0.62$)$ and that of normal epididymis is $0.46-0.68$. (5)

\section{Observations \& Results}

\section{Table 1: Age Distribution}

\begin{tabular}{|l|l|l|}
\hline Age & No. of cases & \\
\hline $0-20$ & 16 & 27 \\
\hline $20-40$ & 30 & 50 \\
\hline $40-60$ & 14 & 23 \\
\hline
\end{tabular}

Nearly 50 percent of patients were young between 20 to 40 years of age. Around 23 percent were older than 40 years

\section{Table 2: Types of Pathology Detected}

\begin{tabular}{|l|l|l|}
\hline Type & No. of Cases & Percentage \\
\hline Inflammatory & 14 & 26 \\
\hline Congenital & 7 & 12 \\
\hline Scrotal hernia & 10 & 16 \\
\hline Infertility & 5 & 8 \\
\hline Torsion & 4 & 7 \\
\hline Tumors & 2 & 3.3 \\
\hline Trauma & 3 & 3 \\
\hline Others & 15 & 26.7 \\
\hline
\end{tabular}

As per tables it is evident that inflammatory lesion with congenital pathology and scrotal hernia were most common pathology accounting for two third of total patients. 
Table 3: Inflammatory Pathology

\begin{tabular}{|l|l|}
\hline Condition & Cases \\
\hline Acute epididymoorchitis & 5 \\
\hline Acute epididymitis & 3 \\
\hline Acute orchitis & 2 \\
\hline Chronic epididymoorchitis & 1 \\
\hline Chronic epididymitis & 1 \\
\hline Fourniers gangrene & 1 \\
\hline Funiculitis & 1 \\
\hline
\end{tabular}

Table 4: Non-inflammatory Swellings

\begin{tabular}{|l|l|}
\hline Condition & cases \\
\hline Hydrocele & 15 \\
\hline Epididymal cyst & 15 \\
\hline Spermatocele & 2 \\
\hline Varicocele & 6 \\
\hline Testicularcyst & 2 \\
\hline Trauma & 3 \\
\hline Neoplasia & 2 \\
\hline Scrotal hernia & 10 \\
\hline
\end{tabular}

Acute epididymitis with Acute epididymoorchitis are two most common inflammatory lesion observed. In non inflammatory conditions hydrocele and epididymal cyst were most common.

\section{Discussion}

A total of 60 cases were examined for scrotal pathology after due consent from the patient. Out of 60 cases in the study, pathological process was detected in all the 60 cases and none of the case showed normal study. Of the 60 cases majority were in the age group of 20-40 years .Non inflammatory pathology constituted the major proportion of cases

\section{Inflammatory Pathology: Inflammatory diseases of scrotal contents include}

- Acute epididymitis and epididymo-orchitis,

- Chronic epididymitis and epididymo-orchitis

- Acute orchitis and Complications of inflammatory diseases of the testis and epididymis.

Acute Epididymitis And Epididymo-Orchitis- It is the most common cause of acute scrotal pain in adolescent boys and adults [2,3]. Prehn sign can differentiates acute epididymitis from torsion testis [4]. When the testis is elevated over the symphysis pubis, pain due to epididymitis reduces. Common causative organisms are Chlamydia trachomatis, Neisseria gonorrhea, Escherichia coli, Pseudomonas, Proteus mirabilis and Mumps.

Ultrasound features- Ultrasound features of acute epididymitis include reduced echogenicity of the testis and epididymis, increased size of the epididymis and the testis [normal-epididymal head : 7-14mm, body: $4 \mathrm{~mm}]$, secondary hydrocele and scrotal wall thickening.

On Color Doppler, increased vascularity and high flow, low resistance pattern was noted with hyperemia. Resistive index is rarely less than 0.5 in normal individuals but is almost always less than 0.5 in epididymo-orchitis, with a peak systolic velocity threshold of $15 \mathrm{~cm} / \mathrm{sec}$ (diagnostic accuracy $-90 \%$ for orchitis and $93 \%$ for epididymitis). Reversal of flow during diastole is suggestive of assosiated venous infarction [5].

Chronic Epididymitis and Epididymo-Orchitis: Inflammation of testis occurs secondary to epididymis, and may occur many years after epididymal inflammation [5]. 
Research Article

\section{Classification [4]}

1. Chronic tuberculous epididymitis / epididymoorchitis - (90\% cases)

2. Chronic non-tuberculous epididymitis / epididymoorchitis (10\% cases)

Chronic tubercular epididymitis/epididymo-orchitis is usually secondary to lung or genitourinary tuberculosis and is predominantly unilateral. Brucellosis, sarcoidosis, leprosy and syphilis are the most common causes of Chronic non-tuberculous epididymitis/ epididymo-orchitis

Ultrasound Features- Tuberculous epididymis may appear homogenously or heterogeneously hyperechoic or may be enlarged and nodular with decreased echogenicity. The appearances of tuberculous testis is similar to tuberculous epididymis and may be heterogeneously or homogenously hyperechoic or may be enlarged and nodular with hypoechoic lesions.

Nontuberculous epididymoorchitis shows diffuse enlargement of epididymis and testis with decreased echogenicity. Calcification can be seen in both tubercular and non-tubercular types. On Color Doppler, non-tuberculous epididymitis shows color within affected epididymis and in tuberculous type, color is seen in periphery in a linear or spotty fashion.

Acute Orchitis- Infection of the testis occurs most commonly due to the contiguous spread from the epididymis. Primary orchitis is rare and is most commonly caused by Mumps (Bilateral in 14-35\% cases) [4].

Ultrasound Features- Ultrasound features of acute orchitis include a diffusely enlarged, hypoechoic testis with probe tenderness. Poorly defined peripheral hypoechoic intratesticular lesions can also be seen $[3,4,6]$. On Color Doppler, increased flow can be seen in the testis.

Intratesticular venous flow is usually difficult to detect in normal testis. Increased and easily detected venous flow is highly suggestive of orchitis [4,6]. Hyperemia and heterogeneity isolated to testis is seen in orchitis, tumour and in transient torsion of testis.

Complications- Complications include reactive hydrocele, abscess formation, pyocele, scrotal wall abscess, funiculitis, testicular ischemia [due to the compression of testicular veins by cord edema], gangrene and atrophy.
Inflammatory Diseases of Scrotal wall

Cellulitis of Scrotal Wall: Common in diabetic, obese and immune-compromised. Ultrasonographic findings include thickening of the scrotal wall and loss of uniform hyperechogenecity of the scrotal wall. Testis and epididymis may be normal. Complications: Scrotal wall abscess.

Fournier's Gangrene -Is scrotal and perineal rapidly progressive, acute, fulminant, polymicrobial, necrotizing fasciitis with high mortality [7- 75\%].

Pathogens: Klebsiella,Proteus, Streptococcus, Staphylococcus, Peptostreptococcus, Escherichia coli and Clostridium perfringens. (4). On HRUS, scrotal wall thickening and loss of normal hyper-echogenecity of scrotal wall with fluid collection within the wall between dartos and cremasteric fascia are seen. Subcutaneous gas in the scrotal wall is the hallmark sign on ultrasound.

Andrea et al, in a series of 117 patients, detected the following pathologies: Inflammatory diseases in 72 cases and non-inflammatory swellings in 45 cases [7]. Thinyu et al, in their study of 84 patients by ultrasonography, found inflammatory lesions in 52 cases, and non-inflammatory swellings in 32 cases [8].

In our study, non-inflammatory conditions constitute the majority of detected pathology, followed by inflammatory swellings. Possible reasons for this variation can be explained by

1) Increased referral of non inflammatory pathology to our tertiary center with treatment of inflammatory pathology at primary center level

2) Generalized increase in percentage of infertility cases

\section{Non Inflammatory, Non Neoplastic Swellings of Scrotum- Hydrocele}

It is defined as an abnormal collection of serous fluid between visceral and parietal layers of tunica vaginalis [9]. It is the most common cause of painless scrotal swelling in clinical practice [10].

1) Congenital [due to patent processusVaginalis] [9]

2) Acquired

a) Primary / Idiopathic

b) Secondary 


\section{Research Article}

Causes of Secondary hydroceles include acute and chronic epididymitis / epididymoorchitis, trauma, malignancy, filariasis, postoperative or post radiotherapy status. Sonography reveals anechoic collection or collection with internal echoes representing cholesterol crystals. Scrotal calculi and parietal wall calcification can also be seen. In infantile hydrocele, tunica and unobliterated processus vaginalis are distended with fluid upto the deep inguinal ring. Idiopathic hydrocele may cause testicular enlargement and increased vascular resistance in the intratesticular arteries. Hence, it may be associated with infertility by interfering with spermatogenesis. Increase in the testicular volume and increased vascular resistance are explained by an increase in impedance to venous and lymphatic flow. [11]

Intratesticular Simple Cyst- They are benign in nature. These cysts of common after trauma and may show calcifications. Sonography shows anechoic imperceptible wall with through transmission and are avascular.

Spermatocele- Usually located in epididymal head, are caused due to obstruction of epididymal tube. They cause retention of sperms. They are multilocular and large [11-13]. Sonography shows 1-2 cm cystic lesion with posterior acoustic enhancement, sometimes showing low echogenic proteinaceous fluid and spermatozoa [14].

Epididymal Cyst- Usually unilocular and occur in the head of epididymis but may be seen in the body and tail also. Commonly occurs in the general population (30\%). Sonography cannot usually distinguish between epididymal cyst and spermatocele. Usually, both are anechoic; however spermatocele may occasionally have a fluid fluid level and may be multi loculated.

Testicular cysts-Incidence: $5-10 \%$. They can occur after trauma or inflammation. Two types- Tunica albuginea cysts [dilated blind ending efferent tubules or mullerian or mesonephric duct remnants] and Intratesticularcysts [usually at mediastinum]. Sonography reveals simple cysts surrounded by normal parenchyma. Complicated cysts show an irregular border, thick wall, mural nodule or calcification suggesting malignancy.

Varicocele - Varicocele is an abnormal dilatation and tortuousity of veins of the pampiniform plexus. Idiopathic varicocele presents between 15-25 years age .Non-compressible varicocele should prompt an evaluation of retroperitoneal mass and left renal vein thrombus/tumour extension. Left sided varicocele is more common than right because of the longer left testicular vein, drainage of left testicular vein into the left renal vein at right angle, pressure by the left renal artery on vein in some cases, and compression by the descending colon loaded with feces. Varicocele leads to infertility by decreasing the sperm count, decreasing the motility of the sperm and altering its morphology. This is because of the decrease in the temperature difference to 0 -1 degree Celsius from the normal difference of 25 degree Celsius to that of rectal temperature because of the varicocele $[15,16]$.

Ultrasound- Plays a very important role in the diagnosis of varicocele and in the follow up post therapy. It is performed in supine and in standing position after $2 \mathrm{~min}$. of standing. Valsalva maneouver is instructed and diameter of dominant vein is examined. Usually abdominal scan is performed to evaluate secondary causes.

Ultrasound Criteria: The largest plexus pampiniformis vein measuring more than $2 \mathrm{~mm}$ in diameter in supine position (or) more than $3 \mathrm{~mm}$ in diameter in standing / semierect position (or) more than $1 \mathrm{~mm}$ increase in size of the largest vein during Valsalva on gray-scale examination (or) more than 2-s retrograde flow during Valsalva maneuver on color Doppler US $[15,16]$.

Varicocele can also be graded as $[15,16]$ :

- Grade 1, slight reflux (<2 s)during Valsalva;

- Grade 2, reflux ( $>2$ s) during Valsalva, but no continuous reflux during the maneuver.

- Grade 3, reflux in rest during normal respiration or continuously during the entire Valsalva maneuver.

In this study, Varicocele was noted in 6 cases out of which 2 were on left side and one on right side. Bilateral varicocele noted in 3 cases $(50 \%)$. Varicocele was detected in patients presenting with symptoms like scrotal swelling, pain, and infertility. Among 6 patients who presented clinically with infertility, varicocele was noted in all 6 cases.

In the present study, the positive predictive value of color Doppler sonography in identifying varicoceles in cases of male infertility, as compared to physical examination was studied. The sensitivity of colour Doppler was (100\%) and positive predilection value (90\%), compared to physical examination. These findings were comparable to previous similar study by Randall B Meacham [17] et al and Petros J A et al [18]. 
Neoplastic Swellings of Scrotum- Neoplastic swellings of the scrotum can be classified into germ cell neoplasms, sertoli-leydig cell or mesenchymal neoplasms and secondary neoplasms [19]. The germ cell neoplasms are further subclassified into the following types-Seminoma, Embryonal cell carcinoma, Teratoma, Endodermal sinus tumor or yolk sac tumor and choriocarcinoma. Secondary neoplasms include reticuloendothelial neoplasms like lymphoma and leukemia and metastasis from Ca lungs, GI tumors, Ca prostate, melanoma, sarcoma and Ca kidney [19].

Seminoma: Most common germ cell neoplasm, common in 30-40 years age group and almost never in infants. They have the best prognosis among germ cell tumours. Cryptorchidism is a well-known risk factor.

Three types -Typical (85\%), Anaplastic (5-10\%), Spermatocytic(4-6\%). Sonography reveals smooth marginated, lobulated, or irregular homogenous, hypoechoic mass lesion without calcification. Multiple, small, focal, cystic areas can be seen but rare. Retroperitoneal lymphadenopathy can be seen $(25 \%$ cases).

In the present study, 2 cases of neoplasms were studied-relatively less number in the study because of the low frequency of their occurrence. Clinically they presented as scrotal swellings with occasional pains. Sonographic features of one of the cases was suggestive of a seminoma while the other of a lymphoma. Sonography was followed by surgical excision and biopsy confirmed the diagnosis.

\section{Conclusions and Summary}

The advantages of High frequency Ultrasound and color Doppler include non-invasiveness, lack of ionizing radiation, simplicity, wide availability, cost effectiveness and repeatability. High frequency ultrasonography is highly sensitive in differentiating solid from cystic scrotal masses. High frequency real time sonography is highly sensitive in distinguishing scrotal mass as either testicular or extra testicular masses and is clearly superior to clinical diagnosis.

High frequency ultrasonography is invaluable in demonstrating normalcy of testes and epididymis in the presence of large hydroceles. High-frequency ultrasonography enables clear demonstration of the morphological alterations associated with acute scrotal inflammatory diseases. Color Doppler sonography is highly sensitive in diagnosing acute scrotal pathology and accurately differentiates testicular ischemia/torsion from acute inflammatory diseases.

High frequency ultrasonography with Doppler is highly sensitive in demonstrating sub clinical cases of varicoceles.

We conclude that High-frequency ultrasonography and color Doppler sonography is an extremely valuable tool in evaluation of scrotal and testicular pathologies.

Funding: NIL

Permission from IRB: Yes

Conflicts of interest: The authors report no conflicts of interest

\section{References}

1. Mirochnik B, Bhargava P, Dighe MK, Kanth N Ultrasound evaluation of scrotal pathology Radiol Clin North Am. 2012 Mar;50(2):317-32, vi. doi:10.1016/j.rcl.2012.02.005.

2. Wright S, Hoffmann B. Emergency ultrasound of acute scrotal pain. Eur J Emerg Med.2015 Feb;22(1):2-9. doi: 10.1097/MEJ.0000000000000123.

3. Sommers D, Winter T.Ultrasonography evaluation of scrotal masses. Radiol Clin North Am. 2014 Nov;52(6):1265-81. doi: 10.1016/j.rcl.2014.07.014

4. Dogra VS, Gottlieb RH, Oka M, Rubens DJ. Sonography of the scrotum. Radiology. 2003 Apr;227(1):18-36. Epub 2003 Feb 28.

5. Brown JM, Hammers LW, Barton JW, et al. Quantitative Doppler assessment of acute scrotal inflammation. Radiology. 1995 Nov;197(2):427-31.

6. Farriol VG, Comella XP, Agromayor EG, Creixams XS, Martinez De La Torre IB. Gray-scale and power Doppler sonographic appearances of acute inflammatory diseases of the scrotum. $\mathrm{J}$ Clin Ultrasound. $2000 \mathrm{Feb}$;28(2):67-72.

7. D'Andrea A, Coppolino F, Cesarano E, et al. US in the assessment of acute scrotum. Crit Ultrasound J. 2013 Jul 15;5 Suppl 1:S8. doi: 10.1186/2036-7902-5S1-S8. Epub 2013 Jul 15.

8. Thinyu S, Muttarak M. Role of ultrasonography in diagnosis of scrotal disorders: a review of 110 cases. Biomed Imaging Interv J. 2009 Jan;5(1):e2. doi: 10.2349/biij.5.1.e2. Epub 2009 Jan 1. 


\section{Research Article}

9. Frush DP, Sheldon CA. Diagnostic imaging for pediatric scrotal disorders. Radiographics. 1998 JulAug;18(4):969-85..

10. Arjhansiri K, Vises N, Kitsukjit W. Sonographic evaluation of the intrascrotal disease. J Med Assoc Thai. 2004 Sep;87 Suppl 2:S161-7..

11. Ismail Mihmanli, FatihKantarc. Sonography of scrotal abnormalities in adults- an update. Diagn Interv Radiol. 2009 Mar;15(1):64-73.

12. Sung EK, Setty BN, Castro-Aragon I. Sonography of the pediatric scrotum: emphasis on the Ts--torsion, trauma, and tumors. AJR Am J Roentgenol. 2012 May;198(5):996-1003. doi: 10.2214/AJR.11.8034.

13. Bhatt S, Jafri SZ, Wasserman N, Dogra VS. Imaging of non-neoplastic intratesticular masses. Diagn Interv Radiol. 2011 Mar;17(1):52-63. doi: 10.4261/1305-3825.DIR.3116-09.0. Epub 2010 Jun 30

14. Blair RJ. Testicular and scrotal masses. Pediatr Rev. 2014 Oct;35(10):450-1; discussion 451. doi: 10.1542/pir.35-10-450.
15. Wolverson MK, Houttuin E, Heiberg E, Sundaram M, Gregory J. High Resolution Real Time Sonography Of Scrotal Varicocele. AJR Am J Roentgenol. 1983 Oct;141(4):775-9.

16. Carkaci S, Ozkan E, Lane D, Yang WT. Scrotal sonography revisited. J Clin Ultrasound. 2010 Jan;38(1):21-37. doi: 10.1002/jcu.20642

17. Meacham RB, Townsend RR, Rademacher D, Drose JA. The incidence of varicoceles in the general population when evaluated by physical examination, gray scale sonography and color Doppler sonography. J Urol. 1994 Jun;151(6):1535-8.

18. Petros JA, Andriole GL, Middleton WD, Picus DA. Correlation of testicular color Doppler ultrasonography, physical examination and venography in the detection of left varicoceles in men with infertility. J Urol 1991 Apr;145(4):785-788.

19. Woodward PJ, Sohaey R, O'Donoghue MJ, Green DE. From the archives of the AFIP: tumors and tumorlike lesions of the testis: radiologic-pathologic correlation. Radiographics. 2002 Jan-Feb;22(1):189216.

\section{How to cite this article?}

Narra R, Pasupuleti B, Kamaraju SK, Jukuri N. Sonological Evaluation of Scrotal Pathology by High Resolution Ultrasound and Color Doppler. Int J Med Res Rev 2015;3(1):90-96. doi: 10.17511/ijmrr.2015.11.15 